\title{
INVESTIGATING HUMAN-MACHINE INTERFACES' EFFICIENCY IN INDUSTRIAL MACHINERY AND EQUIPMENT: A KENYAN CONTEXT
}

\author{
Silas M. Nzuva \\ CloudFuse Systems, Nairobi, Kenya
}

\begin{abstract}
The twenty-first century has seen a vast technological revolution characterized by the development of cyber-physical systems, integration of things, and new and computationally improved machines and systems. However, there have been seemingly little strides in the development of user interfaces, specifically for industrial machines and equipment. The aim of this study was to assess the efficiency of the human-machine interfaces in the Kenyan context in providing a consistent and reliable working environment for industrial machine operators. The researcher employed a convenient purposive sampling to select 15 participants who had at least two years of hands-on experience in machines operation, control, or instrumentation. The results of the study are herein presented, including the recommendations to enhance workforce productivity and efficiency.
\end{abstract}

\section{KEYWORDS}

User interface, human-machine interface, industrial machine operation, user interface efficiency.

\section{INTRODUCTION}

In the modern world that has seen the development of autonomous machines and systems, the utilization of an effective and efficient interface is critical. Essentially, Human Machine Interface (HMI) is a software application that runs on specific hardware and is capable of taking the user input and giving a specific output [1]. At its best, an HMI receives the user inputs, which may be in the form of hand gestures, keyboard inputs, pointing devices such as a mouse, sound (in advanced systems), etc., to issue commands to the machine to perform specific operations. The HMI also presents feedback (output) from the machine to the user, which may be in the form of textual or graphics display, sound, or a combination of the two [1]. It is essential to note the HMI entails a combination of both hardware and software, which enable the user to operate a given machine. The software is usually installed on the hardware. The user operates the machine through an interface (often a graphical or textual display), which gets the user commands, converts them into instructions, and issues them to the machine. It also gets the machine output and converts it into appropriate feedback that is comprehensible by the user [2].

While the commands issued may direct the system to perform a specific function, the feedback may entail an acknowledgment of whether the operation was successful or not. Analytically, some decades ago, machine instrumentation and control relied on the use of pushbuttons, such as the switches, to control different operations [3]. With time, technological revolution in the industry saw the emergence of integrated circuits and electronic panels that could control different systems simultaneously, though the control was still manual and was referred to as manmachine interface [3]. Later on, the electronic panels and integrated circuits were taken over by advanced circuit boards, computers and application programs that paved the way for the modern- 


\section{International Journal of Information Technology, Control and Automation (IJITCA)}

Vol.11, No.4, October 2021

day Human-Machine Interface. As at present, HMIs are capable of controlling a wide range of devices, from standalone machines to networked systems in different plants across the globe. As at present, HMI has seen the adoption of visualization, which in turn has greatly shaped industrial engineering processes through increased efficiency and accuracy in operations.

For high efficiency and heightened human-machine interactions to be attained, the designers must fully understand the loopholes in the current system and come up with plans and strategies aimed at curbing them in future designs. As at present, all the industries are experiencing a vast technological revolution, and so has industrial engineering. The need to make more autonomous, efficient, cost-effective and durable machines and systems is now clear than ever. While business organizations are on the verge of gradually procuring and implementing production systems and machinery, only a few understand the need to consider the machine interfaces aspect, as the majority only adopt such machines as a necessary change to keep up with the competitors. In essence, firms that invest in equipment, machinery, and systems without considering all the productivity aspects such as machine interface not only do they risk financial resource misappropriation but also may end up thwarting the overall organization performance. The main aim of this study was to establish how efficient the current machine interface is in providing a consistent and reliable operating environment for carrying out industrial tasks.

\section{MeTHODS}

The research methodology adopted must support the data collection procedures and the subsequent analysis [4]. The latter should, therefore, encompass the research methods, the data collection method, the sampling techniques, and the data analysis techniques [5]. A quantitative research design was employed through the use of a survey questionnaire for data collection. The survey questionnaire was fully structured, implying that all the questions were closed-ended. As stated by [4], a closed-ended questionnaire is very useful in providing the user with pre-coded data for easy statistical analysis and interpretations. Nevertheless, the researcher also mentions that in instances where a fully structured questionnaire is not deemed effective, the researcher can choose to employ a semi-structured questionnaire or an unstructured questionnaire [4].

The study was conducted in Kenya. The researcher employed convenient purposive sampling, whereby a group of 15 participants was identified to complete the survey. The main inclusion criteria for the participants were:

(1) Good knowledge of the theme of human-machine interface

(2) At least two years of experience in interacting with modern machines and equipment

(3) Currently engaged as hands-on industrial machine operator, supervisor, or first-line manager in machine operations.

(4) Working in Kenya.

Prior to the administration of the survey questionnaire, all the participants were required to give their consent. The participation was anonymous, confidential, and voluntary. Moreover, the participants were free to withdraw their participation at any time during the study.

The survey questionnaire was designed and administered electronically. The survey comprised questions that the researcher felt that would aid in completely achieving the research goal presented in the introduction section. As presented in [6], electronic design and administration of surveys has become common in today's studies due to the efficiency of the design process, ability to automatically collect the researcher responses, and finally, the ability to eliminate the possibility of submission of incomplete or uncompleted survey questionnaires. The designed survey questionnaire was distributed to the participants through web links that directed the participants to the web page with the questions 
The data obtained from the questionnaire was analysed electronically through the use of the Microsoft Office Excel application program, 2016 version. A five-point Likert scale was used as the unit of measurement for the participants' responses. Each option on the Likert scale was assigned a specific weight, with the negative extreme having the lowest weight and the positive extreme the highest weight. The scale used is presented in table 1 below.

Table 1. The Likert scale used

\begin{tabular}{|l|l|l|l|l|}
\hline Likert Scale & Very satisfied & Excellent & Very good & Weight \\
\hline Strong Agree & Satisfied & Above average & Good & 4 \\
\hline Agree & $\begin{array}{l}\text { Neither satisfied } \\
\text { nor dissatisfied }\end{array}$ & Average & Acceptable & 3 \\
\hline $\begin{array}{l}\text { Neither Agree nor } \\
\text { Disagree }\end{array}$ & Dissatisfied & Below average & Poor & 2 \\
\hline Disagree & Very dissatisfied & Very poor & Very poor & 1 \\
\hline Strongly Disagree & & \\
\hline
\end{tabular}

\section{RESULTS}

The responses presented are from the 15 participants who completed the survey. All the sampled participants turned in a fully filled questionnaire $(n=15)$; the response rate was therefore $100 \%$. Of the 15 participants, 6 were females $(40 \%)$ while 8 were males $(60 \%)$.

First, the participants were asked how they would rate their current machine interface interaction. $60.00 \%$ of the participants rated their interaction to be very good, $13.33 \%$ rated the interaction to be acceptable, while the remaining $26.67 \%$ rated the interaction as good.

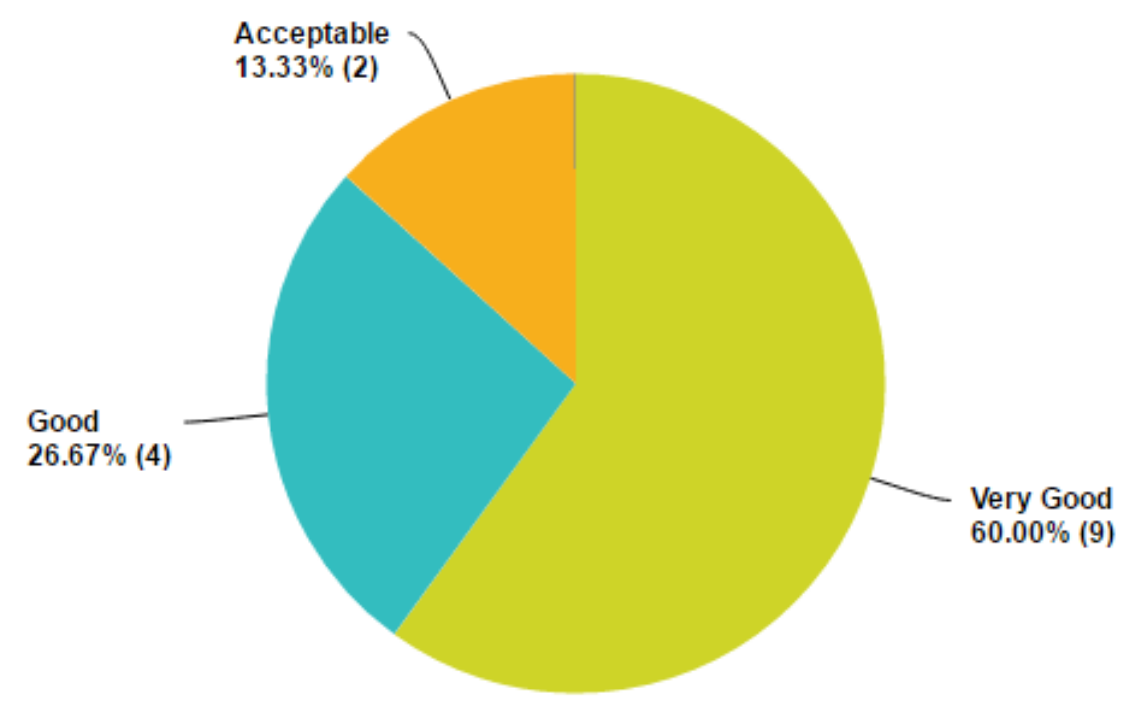

Figure 1. Rating of the participants' current user-machine interface interaction

An average score of 4.5 was obtained, characterized by 0.74 standard deviations. Basically, the standard deviation is a bit little, indicating little variations in the participants' responses. The 4.5 score, when rounded off to the nearest whole number, lies in the "very good" option on the Likert scale, which indicates that the majority of the participants considered their interaction with the machine interfaces to be excellent. 
Afterwards, the researcher also evaluated the perspectives of the participants towards the usability of the machine interfaces they have interacted with over the last two years. In this question, it was unveiled that $60.00 \%$ of the participants felt that the usability was above average, $33.33 \%$ felt the usability was excellent, and $6.67 \%$ considered the usability to be average. It is critical to note that no scores were recorded for below-average and very poor options. Additionally, a weighted average of 4.3 was obtained, coupled with a standard deviation of 0.59

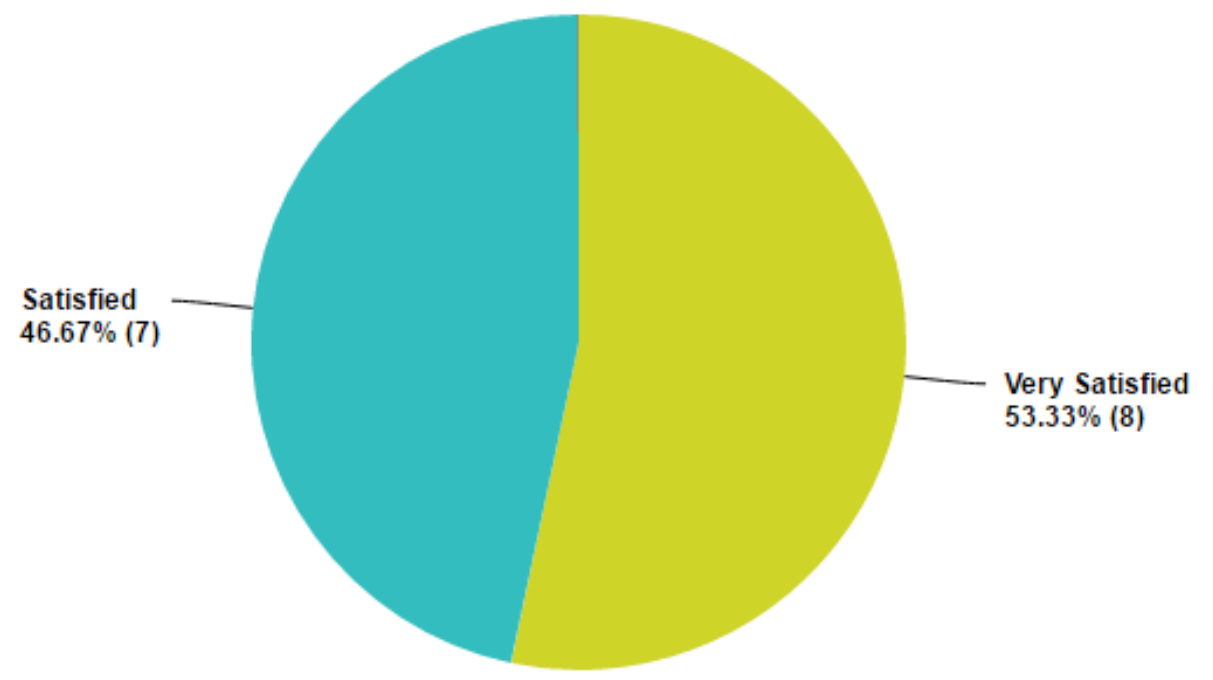

Figure 2. Usability of the human-machine interfaces

As observable for figure 2 above, the majority of the participants feel that the usability of the current machine interfaces is above average, which indicates that the majority of the people are literally satisfied with the interfaces that they do interact with when using machines

The participants were again assessed on their level of satisfaction with their current machine interfaces. Specifically, the users were asked how they would rate their satisfaction levels with the machine interface. $53.33 \%$ of the participants claimed to be very satisfied, while the remaining $46.67 \%$ were satisfied. 


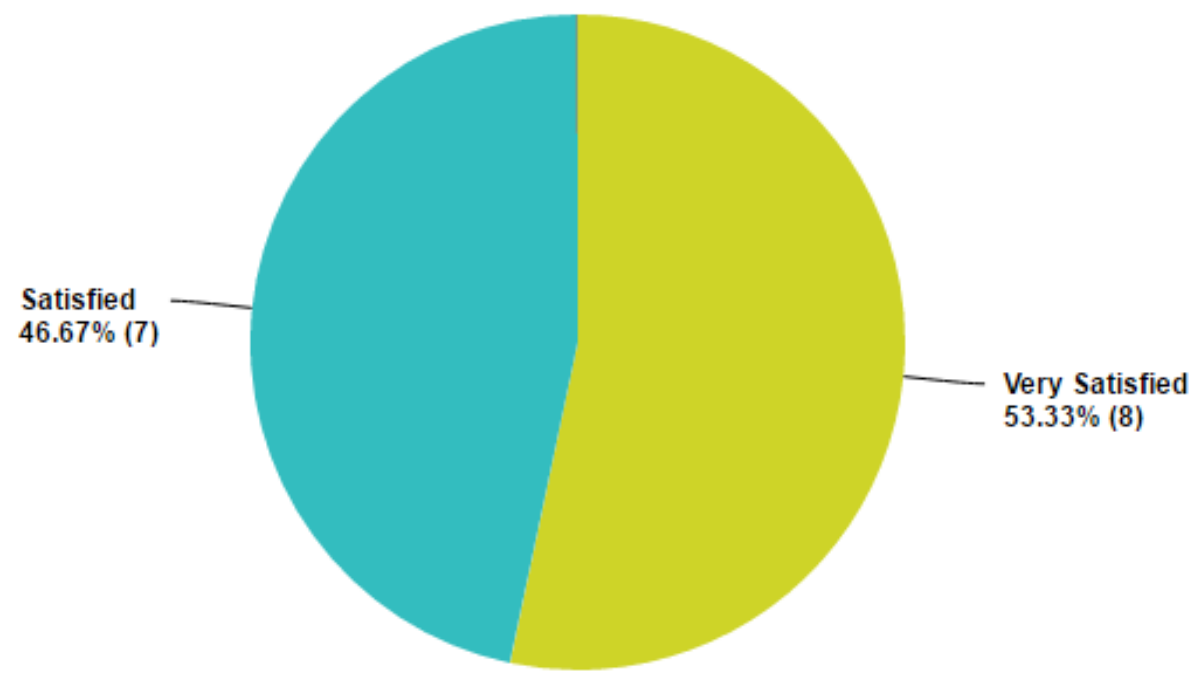

Figure 1. User satisfaction with human-machine interface

An average score of 4.5 was recorded, with a 0.52 standard deviation. This shows that there were little variations in the participants' responses, and additionally, all the scores recorded were towards the positive extreme. It is crucial to note that not a single score was recorded for the neither satisfied nor dissatisfied, dissatisfied, and very dissatisfied positions.

The survey also inquired about the challenges that the users face when using the machine interface. As observable from the table below, $53.33 \%$ felt that some crucial functionalities in the system are not easily identifiable, $40.00 \%$ claimed that they do not get visual/sound feedback whenever they issue a command through the interface, $26.67 \%$ considered the machine interfaces to be tiresome and challenging when using, $20.00 \%$ claimed that the machine interfaces lacked options for adjusting the screen resolution and graphics, $20.00 \%$ perceived the interface colors and design not be appealing. The lowest score was recorded in the lack of crucial functionalities for the machine operations. The results in this question are well presented in table 2 below

Table 2. Notable problems when using human-machine interfaces

\begin{tabular}{|l|c|}
\hline Problems with human-machine interfaces & Responses- \\
\hline The system "freezes/does not respond" & $33.33 \%$ \\
\hline Some crucial functions are not easily identifiable & $53.33 \%$ \\
\hline Navigating the interface is considerably tiresome/challenging & $26.67 \%$ \\
\hline The interface colors and design is not appealing & $20.00 \%$ \\
\hline When I tap/command the system, I do not get visual/sound feedback & $40.00 \%$ \\
\hline The interface lacks options for adjusting the screen graphics and resolution & $20.00 \%$ \\
\hline $\begin{array}{l}\text { The system lack some functionalities that are crucial for the machine } \\
\text { operations }\end{array}$ & $6.67 \%$ \\
\hline
\end{tabular}


Finally, the survey also inquired about the areas of improvement that the participants would recommend on human-machine interfaces.

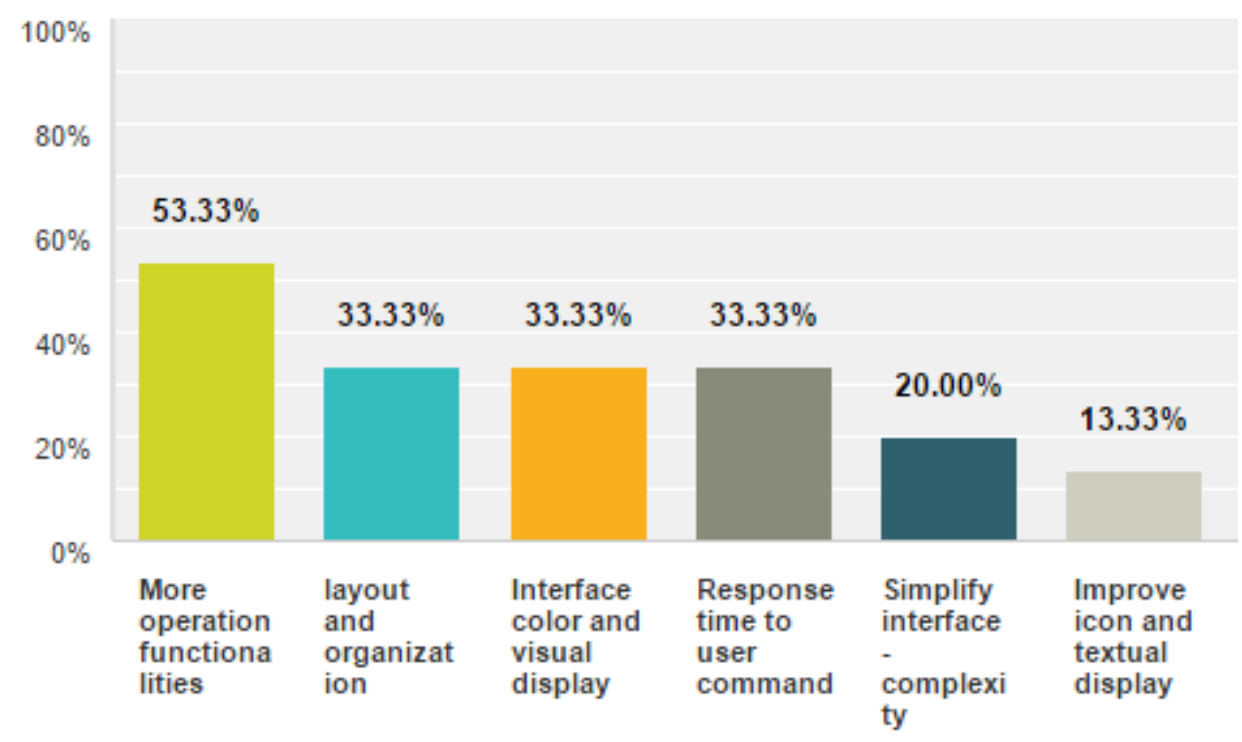

Figure 2. Recommendations for improving human-machine interfaces

As presented in figure 4 above, in this question, $53.33 \%$ of the participants felt that more operations functionalities needed to be added to the interfaces, $33.33 \%$ recommended for the layout and interface organization improvement, another $33.33 \%$ recommended improvement in color and visual displays, another $33.33 \%$ recommended improvement in response time, $20.00 \%$ wanted simplification of the interface, and finally, $13.33 \%$ wanted improvement of icons and textual display.

This study was aimed at assessing the present-day human-machines interfaces efficiency in providing a consistent and reliable operating environment for carrying out industrial tasks. Based on the survey results, it is clear that the majority of the users perceive their current interaction with the machine interfaces as "very good. This may be due to the technological revolution in the 21 st century that has seen a dramatic improvement in all facets of industrial engineering. It is critical to note that not all machines have an electronic human-machine interface, but however, the industrial engineering discipline has seen a significant revolution in the 21 st century, with the development of machines that have simplified and highly efficient human interfaces. The basic functionality of the HMI component in any given machine is to control, monitor, and give feedback regarding the state of the equipment or machine in [7].

The variations in scores regarding user satisfaction and interface usability indicate the need to enhance the efficiency of the interfaces. The efficiency of a machine is not just determined by its output per unit time but rather, how effectively the users are able to interact with it [8]. In industrial engineering, core equipment and machines are embedded with a human-machine interface module, a component that enables the users to monitor and control the machine operations. Owing to this, the essence of having a highly functional human-machine interface cannot be underestimated.

From the survey, it is observable that the human-machine interaction remains a very crucial industrial design principle in the engineering disciplines. In any given machine, the designer must 
have in mind how the user will interact with it in a manner that depicts cost-effectiveness and operational efficiency [9]. To achieve optimal effectiveness in the interface usability, satisfaction, and user interaction, the system engineers must adhere to the principles of human-machine interactions and seek to enhance the communication between the two by coming up with better designs of the machine interfaces, based on the identified loopholes from the current systems [10]. As such, any human-machine interface should be oriented towards enhancing machine operational efficiency in the short term and boost organizational performance in the long term.

\section{Conclusion}

In the $21^{\text {st }}$ century, the majority of the industrial machines have interfaces, which often act as the core units through which the human communicates with the machines. The main aim of the research was to establish how efficient the current machine interface is in providing a consistent and reliable operating environment for carrying out industrial tasks. The findings from the research indicate that although the usability of the current HMI is acceptable, the users' satisfaction levels are still low. For the study findings, there is still the need to improve six main areas. These include; (i) adding more functionalities to the interfaces, (ii) improving the interface layout and organization, (iii) improving the interface color and visual display, (iv) enhancing the response time to the user commands, (v) simplifying the interface, and lastly, (vi) improving the icon and textual display. The above recommendations are written in order of their prevalence, based on the survey scored from the responses.

This paper stresses the need to ensure more innovative, friendly, and highly operable interfaces are developed. The research also aids organization managers in understanding how to identify machines with exceptional interface designs, which results in increased operational efficiency. Business enterprises are deemed to benefit in the long run from increased machine efficiency due to better designs of the interface module.

\section{REFERENCES}




\section{International Journal of Information Technology, Control and Automation (IJITCA)}

Vol.11, No.4, October 2021

[1] Naujoks, F., Forster, Y., Wiedemann, K., \& Neukum, A. (2017). A Human-Machine Interface for Cooperative Highly Automated Driving. In Advances in Human Aspect

[2] Guo, W., Sheng, X., Liu, H., \& Zhu, X. (2017). Toward an Enhanced Human-Machine Interface for Upper-Limb Prosthesis Control with Combined EMG and NIRS Signals. IEEE Transactions on Human-Machine Systems

[3] Katzel, J. (2012). Information systems: The evolution of the HMI. Control Engineering. Retrieved 3 March 2017, from http://www.controleng.com/single-article/information-systems-the-evolution-ofthe-hmi/d643c1d8644f73884df2c0827cb31f38.html

[4] Baskerville, R. L., \& Wood-Harper, A. T. (2016). A critical perspective on action research as a method for information systems research. In Enacting Research Methods in Information Systems: Volume 2 (pp. 169-190). Springer International Publishing

[5] Bryman, A., \& Bell, E. (2015). Business research methods. Oxford University Press, USA

[6] Cohen, L., Manion, L., \& Morrison, K. (2013). Research methods in education. Routledge

[7] Parasuraman, R., Sheridan, T. B., \& Wickens, C. D. (2000). A model for types and levels of human interaction with automation. IEEE Transactions on systems, man, and cybernetics-Part A: Systems and Humans, 30(3), 286-297

[8] Lech, M. M., Hill III, T. D., Arvidson, A. L., Paddock, S. R., \& Hussain, A. (2003). U.S. Patent No. 6,539,271. Washington, DC: U.S. Patent and Trademark Office

[9] Nachreiner, F., Nickel, P., \& Meyer, I. (2006). Human factors in process control systems: The design of human-machine interfaces. Safety Science, 44(1), 5-26

[10] Bach-y-Rita, P., \& Kercel, S. W. (2003). Sensory substitution and the human-machine interface. Trends in cognitive sciences, 7(12), 541-546 